\title{
Fire-derived organic carbon in soil turns over on a centennial scale
}

\author{
N. Singh ${ }^{1}$, S. Abiven ${ }^{1}$, M. S. Torn ${ }^{2}$, and M. W. I. Schmidt ${ }^{1}$ \\ ${ }^{1}$ University of Zurich, Department of Geography, Winterthurerstrasse 190, Zürich 8057, Switzerland \\ ${ }^{2}$ Lawrence Berkeley National Laboratory, Berkeley, CA 94720, USA \\ Correspondence to: S. Abiven (samuel.abiven@geo.uzh.ch)
}

Received: 3 November 2011 - Published in Biogeosciences Discuss.: 16 December 2011

Revised: 16 April 2012 - Accepted: 4 July 2012 - Published: 1 August 2012

\begin{abstract}
Pyrogenic carbon (PyC), the residue of an incomplete combustion of biomass, is considered as a carbon (C) sink due to its assumed stability in soil. PyC turnover time estimated using two modelling approaches, based on data from 16 published studies $(n=54)$ on PyC degradation, ranged from a decadal to centennial time scale, varying with initial biomass type, pyrolysis temperature, and incubation or field study. The average turnover time using a one-pool approach was $88 \mathrm{y}$, and the best estimate using a two-pool approach was $3 \mathrm{y}$ for a fast-cycling pool and $870 \mathrm{y}$ for a slow-cycling pool. Based on this meta-analysis, PyC cannot be assumed to persist in soils for thousands of years, and its use as a strategy for offsetting carbon emissions requires prudence and further research.
\end{abstract}

\section{Introduction}

Wildfires transfer approximately 0.05 to $0.2 \mathrm{Pg} \mathrm{C} \mathrm{yr}^{-1}$ to soil (Seiler and Crutzen, 1980; Kuhlbusch, 1998) as incomplete combustion residue of biomass, known as pyrogenic carbon (PyC) (Goldberg, 1985). Climate change is projected to increase wildfire frequency in many parts of the world (Flannigan et al., 2006), which could modify the input of PyC and consequently the terrestrial carbon cycle (Westerling et al., 2006). PyC is ubiquitous in the environment and ranges from $2 \%$ to $45 \%$ of the total soil organic carbon (SOC) in terrestrial systems (Bird et al., 1999; Schmidt et al., 1999; Skjemstad et al., 2002; Lehmann et al., 2008). Some researchers suggest that $\mathrm{PyC}$ forms a slow-cycling $\mathrm{C}$ pool in the soil (Preston and Schmidt, 2006; Marschner, 2008). If so, conversion of plant biomass to $\mathrm{PyC}$ would represent a transfer of fastercycling biomass-C to slower-cycling $\mathrm{C}$ in soils (Ohlson et al., 2009) and is therefore expected to act as a C sink (Seifritz,
1993; Marris, 2006). In the last decade, $\mathrm{PyC}$ has gained interest as a strategy for sequestering atmospheric $\mathrm{CO}_{2}$ to partly offset carbon emissions (Lehmann et al., 2006).

The ability of PyC to act as a carbon sink depends on its persistence in the soil. $\mathrm{PyC}$ is widely considered to be relatively "inert" (Forbes et al., 2006) because PyC has been preserved in geological samples or strata (Forbes et al., 2006), archaeological sites (Schmid et al., 2002; Glaser, 2007), and old anthropogenic soils (Glaser et al., 2000; Knicker, 2011; Glaser and Birk, 2012). Moreover, in some experiments, PyC was resistant to chemical oxidants (Skjemstad et al., 1996) and contributed to the oldest soil organic carbon (SOC) pool in some Australian soils (Krull et al., 2006). Based on the ${ }^{14} \mathrm{C}$ age of PyC macro-pieces/charcoal (Pessenda et al., 2001; Schmidt et al., 2002) and budget calculations (Forbes et al., 2006), PyC age in soil has been estimated to be on the scale of hundreds to ten thousand years (Liang et al., 2008). The limitation of using radiocarbon age to estimate turnover time is that we rarely have knowledge of the input rate (or, for isolated systems, initial stock when the radiocarbon "clock" started), which would be needed to estimate turnover times.

Recent studies, however, observe transformation and mineralization of PyC over weeks to yearly timescales (Hamer et al., 2004; Bruun et al., 2008; Hilscher et al., 2009; Hilscher and Knicker, 2011) and significant losses of PyC from the soil profile in long-term field studies (Bird et al., 1999; Hammes et al., 2008b; Nguyen et al., 2008). PyC is presumed to degrade physically (Carcaillet and Talon, 1996; Carcaillet, 2001; Lehmann et al., 2003; Hammes and Schmidt, 2009) and chemically by abiotic (Lehmann et al., 2005; Cheng et al., 2006; Hockaday et al., 2006) and/or microbial agents (Potter, 1908; Shneour, 1966; Goldberg, 1985). Incubations have identified abiotic (Cheng et al., 2006) and biotic oxidation processes (Potter, 1908; Hamer et al., 2004; Kuzyakov 
et al., 2009; Zimmerman, 2010) as important mechanisms of $\mathrm{PyC}$ degradation. Turnover times of PyC reported in most of these experimental studies ranged between a hundred and a thousand years.

These recent observations contradict the perception that $\mathrm{PyC}$ persists in soil for millenia. The uncertainty in PyC persistence is accompanied by a basic lack of understanding about PyC dynamics in soil. Spokas (2010) observed an increase in stability of $\mathrm{PyC}$ with a decrease in the $\mathrm{O}: \mathrm{C}$ molar ratio of PyC. However, the correlation between half life of $\mathrm{PyC}$ and the $\mathrm{O}$ : C molar ratio was based on different methodological approaches to estimate the mean residence time of PyC. Therefore, to reconcile the apparent discrepancies between assumed persistence of $\mathrm{PyC}$ based on radiocarbon age and fairly rapid degradation of $\mathrm{PyC}$ as observed in experiments, we assembled data from published studies on PyC losses from soil and, for the first time, calculated turnover times within and across all studies with one consistent approach.

\section{Materials and methods}

\subsection{Data set collection from the literature}

We compiled data from published studies $(n=54$ data sets from 16 studies, Supplement Table 2) on PyC degradation. We investigated turnover times of $\mathrm{PyC}$ using two previously published models to describe PyC decomposition and/or soil organic matter dynamics (Supplement Table 1). These models should be seen as a way of approximating characteristic time constants rather than quantifying the exact dynamics (Burnham and Anderson, 2002).

\subsection{One-pool approach}

In the first approach, we used a one-pool exponential decay model in which $\mathrm{PyC}$ is modelled as a single homogeneous $\mathrm{C}$ pool and assumed to follow first-order kinetics (Brodowski, 2005; Cheng et al., 2008b; Hammes et al., 2008b; Nguyen et al., 2008). We assumed that there were no new PyC inputs between time $=0$ and time $=t$ (in years). We calculated the decay rate from the total loss of PyC (sum of all loss processes including leaching, erosion, mineralization, and/or decomposition) relative to the initial stock, to estimate the turnover time of $\mathrm{PyC}$ in the soil with respect to all loss pathways of PyC from the soil to other terrestrial pools or from the terrestrial ecosystem.

Based on these assumptions, the decay rate $k$ is calculated from the loss of PyC over time as follows:

$C_{t}=C_{0} e^{-k t}$

where $C_{t}$ is the remaining stock after time $t, C_{0}$ is the initial stock of PyC (at $t=0$ ), and $k$ is the decay rate $\left(\mathrm{y}^{-1}\right)$. The turnover time $\tau$ is calculated as $\tau=1 / k$.
For the one-pool approach, we calculated turnover times based on two data points for each study, the initial stock of $\mathrm{PyC}$ and final $\mathrm{PyC}$ remaining at the end of the experiment, using Eq. (1). Most studies had only two data points, and the intermediate points that were reported in a few studies (Hamer et al., 2004; Brodowski, 2005; Kuzyakov et al., 2009) were not included for consistency. Further, the compiled data set $(n=54)$ was used to generate a time series stock of PyC (with initial stock at time $t=0$ being $100 \%$ and the last point of each study corresponding to remaining stock at time $t$ in the time series). The one-pool model was fit by constrained non-linear regression, using the chi-square minimization in the IBM SPSS statistics software package for the Mac.

\subsection{Two-pool approach}

In the second approach, PyC decomposition dynamics were calculated using a two-pool exponential model (Hamer et al., 2004; Hilscher et al., 2009; Kuzyakov et al., 2009; Major et al., 2009; Hilscher and Knicker, 2011).The first pool consisted of PyC with a rapid decay rate, $k_{\text {fast }}$, while the second pool was comprised of slowly cycling PyC and was characterized by a slow decay rate, $k_{\text {slow }}$. We assumed that the pools decayed in parallel - in other words that there was no exchange of PyC between pools. Thus,

$C_{t}=x e^{\left(-k_{\text {fast }} t\right)}+(1-x) e^{\left(-k_{\text {slow }} t\right)}$

where $C_{t}$ is the remaining stock after time $t ; x$ is the proportion of initial stock in the fast-cycling PyC pool (at $t=0$ ), $C_{\text {fast }} ;(1-x)$ is the proportion of the slow-cycling pool (at $t=$ $0), C_{\text {slow }} ; k_{\text {fast }}$ and $k_{\text {slow }}$ are decay rate constants $\left(\right.$ year $^{-1}$ ).

Accordingly, the turnover time for the fast-cycling pool $\tau_{\text {fast }}(\mathrm{y})$ is $1 / k_{\text {fast }}$ and for the slow-cycling pool $\tau_{\text {slow }}(\mathrm{y})$ is $1 / k_{\text {slow. }}$.

The two-pool model was fitted to the compiled data set $(n=54)$ (with the initial stock at time $t=0$ and stock at the last point for each study corresponding to the time series decrease in initial stock with time) using the constrained non-linear parameter estimation procedures in the IBM SPSS statistics software package for the Mac. The curve-fitting values were iterative and required initial starting values. To avoid errors due to convergence to local minima of the residual sum of squares (RSS), we adopted convergence criteria as used by Updegraff (Updegraff et al., 1995), where final parameter estimates were accepted only if equations converged to the same values given starting values up to $50 \%$ above and below them. The explained variance for the two-pool model is given in Supplement Table 3.

\subsection{Assumptions}

First, for the one-pool decay model, we accepted the simplification to one homogeneous pool, because the small amount of PyC lost within the first days suggested that the 


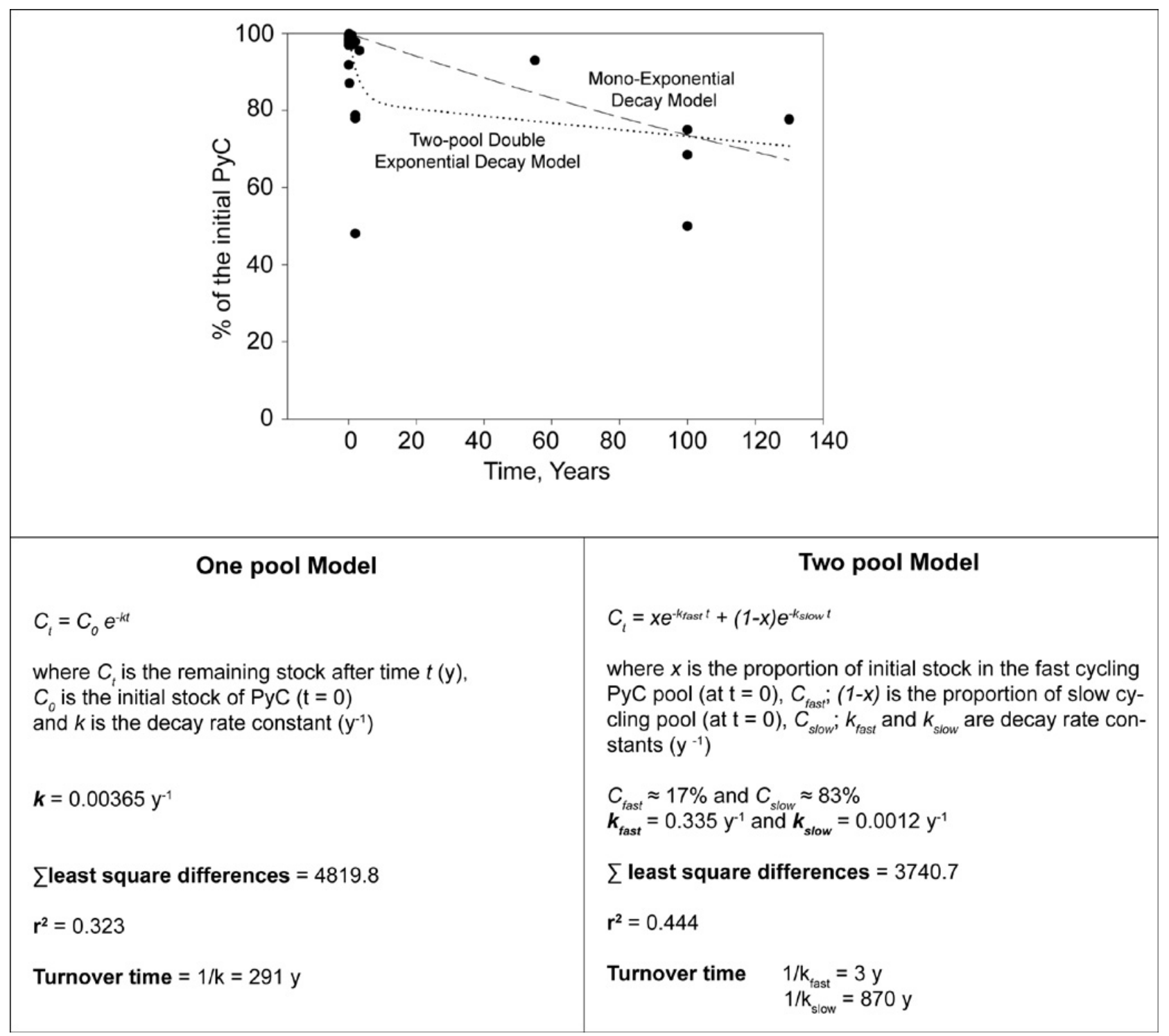

Fig. 1. Parameter estimates for the one-pool exponential and the two-pool exponential model.

fast-cycling pool of PyC in most studies represented only a minor part of the whole and hence the single-pool model may be adequate to capture the bulk dynamics (Derrien and Amelung, 2011). Moreover, the assumption of one pool allowed us to compute and compare turnover times of PyC despite the differences in types of PyC, experimental setup, or analytical method employed in various studies. Further, this assumption was based on "analytical homogeneity" rather than on a "compositional homogeneity", as most studies measure a fraction of the biomass combustion continuum comprised in the mid to high temperature range. Second, first-order kinetics, meaning that the rate of mass loss is a constant proportion of mass, is a simple and robust formulation that is commonly used to describe the turnover of SOM (soil organic matter)(Parton et al., 1988). Third, the assump- tion of no new PyC inputs is justified because the incubation studies were set up in that way, and the field experiments were chosen where inputs had been low (although quantified poorly or not at all) after the initial sample collection. Finally, although the model yields turnover based on all loss mechanisms, we use this as a proxy for PyC decay rates, because the compiled data mostly consist of incubation studies where other loss mechanisms like erosion and leaching were limited. PyC losses by leaching do exist but are small (Abiven et al., 2011). However, erosion could be an important factor in field studies with steep slopes, as shown in Rumpel et al. (2006). However, in the field studies included in this work, erosion is probably very small - for example, in the Chernozem plains (Vasilyeva et al., 2011; Hammes et al., 2008b) and the western Kenyan plateau region (Nguyen et al., 2008). 


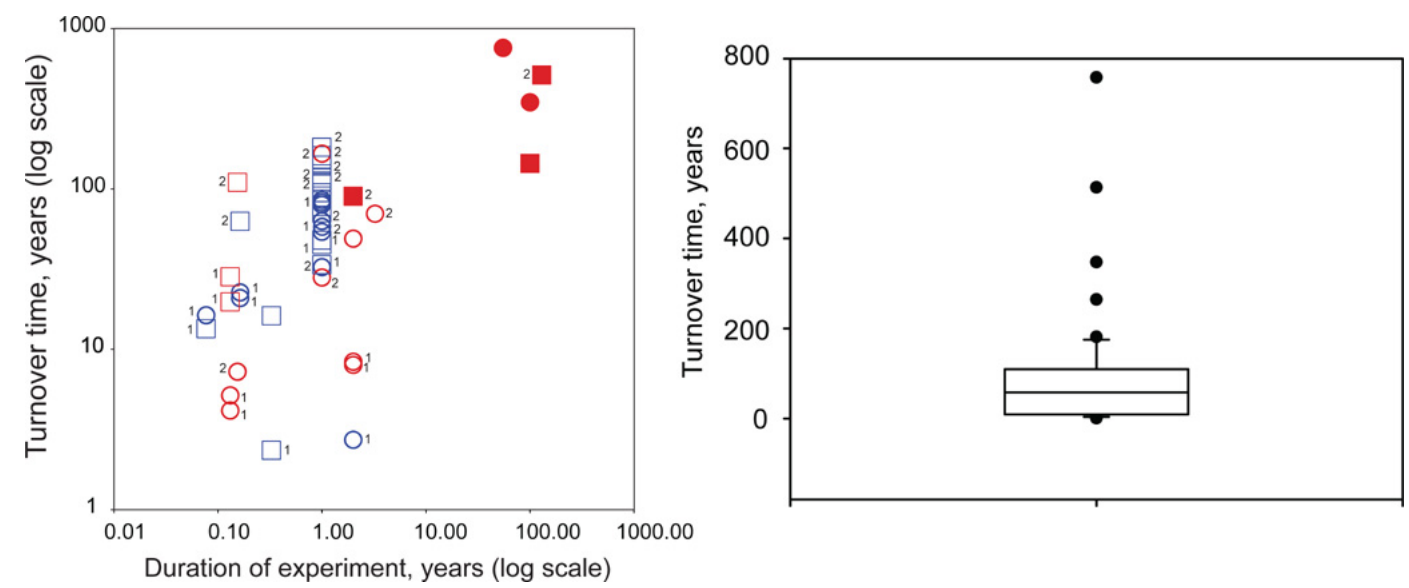

Fig. 2. PyC has an average turnover time of 88 years and ranges from $<1$ y to $750 \mathrm{y}$ based on first-order decay model. Turnover time calculated using first-order decay vs. duration of experiment (left). The empty symbol represents incubation studies, filled symbol represents field-based studies, circles correspond to grass PyC, squares correspond to wood PyC, colour represents sand (blue) and soil (red) medium, the numbers represent temperature of pyrolysis: (1) for $<400^{\circ} \mathrm{C}$ and (2) for $\geq 400^{\circ} \mathrm{C}$. There is a weak relation between experiment duration and individual turnover time $\left(r^{2}=0.49\right)$, showing experiment duration is not the only factor influencing turnover time. Box plot of individual turnover time for each study (right), where filled black circles are outliers beyond 5 th or 95 th percentiles.

Therefore, the data set is restricted to those studies where (1) the initial inputs and stock were known or could be estimated; (2) the initial stock decreased or remained constant with time; and (3) the experimental setup included terrestrial systems.

\section{Results and discussion}

\subsection{Turnover time of PyC for combined dataset}

The turnover time computed for each study using Eq. (1) ranged from $<1$ to $750 \mathrm{y}$ and yielded an average value of $88 \mathrm{y}$ (with standard deviation as $131 \mathrm{y}$ and standard error of mean as 18). The large standard error represents a large variation in the experimental studies. The overall turnover time of PyC computed with the one-pool decay model using model fit by non-linear regression and chi square minimization was 291 y $\left(r^{2}=0.32, n=54\right.$, root mean square error $\left.=10.13\right)$. The turnover time computed with the two-pool model was $3 \mathrm{y}$ for the fast-cycling pool $\left(C_{\mathrm{fast}}=17 \%\right)$ and $870 \mathrm{y}$ for the slow-cycling pool $\left(C_{\text {slow }}=83 \%\right)$ of PyC $\left(r^{2}=0.44\right.$, root mean square error $=8.35$ ). The two-pool model gave a slightly better fit to the data than did the one-pool model (Fig. 1).

The calculated turnover times are much shorter than previously assumed or estimated to date. The higher number of short-term studies in the compiled data set, which mainly capture the fast-cycling dynamics, could influence the overall calculated turnover time to a faster value. Although having faster decay than previously thought, the overall turnover times suggest that $\mathrm{PyC}$ is more stable than all known plantderived organic compound classes in soil, based on low-level
${ }^{13} \mathrm{C}$ labelling experiments (Amelung et al., 2008; Glaser, 2005).

\subsection{Turnover time of $\mathrm{PyC}$ as a function of different factors}

We observed a high scatter in the turnover times between different studies (ranged from $<1$ to 750 years) (Fig. 2). For instance, Brodowski (2005) observed 16-22\% PyC degradation in 104 weeks of incubation study (yielding a turnover time of 8 years), while Shindo (1991) observed no decomposition of grassland plant $\mathrm{PyC}$ in volcanic ash soil for 40 weeks of incubation. This scatter can be partly explained by the different experimental approaches among studies; for instance, a major difference is the experiment duration. Most PyC incubation studies lasted for a few months to a year and were potentially biased towards shorter turnover times (Derrien and Amelung, 2011).

Other factors can also be identified. Edaphic factors influence the decomposition rate of SOM (Trumbore, 2000) and could influence PyC turnover. Additionally, the types of biomass used to make PyC (Franklin, 1951), pyrolysis temperature (Schneider et al., 2010), pyrolysis conditions (e.g. inclusion or exclusion of air), and non-edaphic environmental conditions (Cheng et al., 2008a) may affect PyC turnover in soil.

We grouped the data to see whether these factors influenced turnover times when all other factors were allowed to vary, namely (1) incubation vs. field studies; (2) type of biomass (grass vs. wood); (3) pyrolysis temperature $\left(<400^{\circ} \mathrm{C}\right.$ and $\left.\geq 400^{\circ} \mathrm{C}\right)$; and (4) quartz sand vs. soil medium (Fig. 3). Data were not grouped by other factors that control SOM decomposition - like climate, degree of 


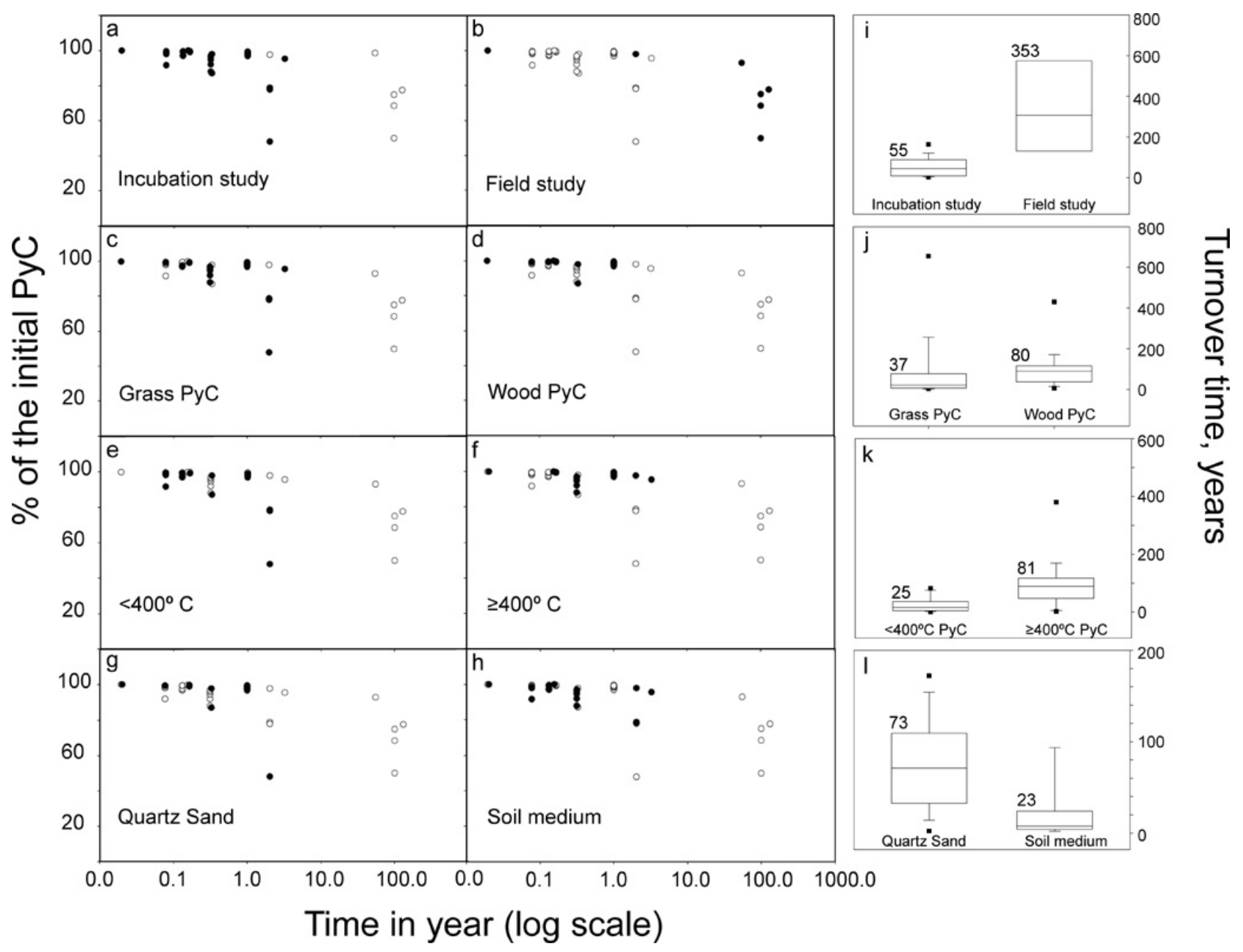

Fig. 3. Pyrogenic stock expressed as percentage of the initial from the data reported in literatures. Circles represent all data points and solid circles represent the grouped data set, namely (a) incubation study, (b) field study, (c) grass PyC, (d) wood PyC, (e) pyrolysis temperature $<400{ }^{\circ} \mathrm{C}$, (f) pyrolysis temperature $\geq 400^{\circ} \mathrm{C}$, (g) sand medium and (h) soil medium. The time is expressed in years (log scale). The box plot (right) of turnover time of each variable (i)-(l), where squares are outliers beyond 5th or 95th percentiles and numbers denote average turnover time. The calculated turnover time varies from decades to century.

soil development, soil types, topography, and biota - because they were either not reported or were kept constant in most studies. We computed individual turnover times for each data set $(n=54)$ using Eq. (1) and computed the range, average, and variation of turnover times associated with each of the above-mentioned factors. To avoid the effect of the differences due to time scale, we only considered incubation studies and therefore used Eq. (1) for the grouped data. For comparison between incubation studies and long-term field studies, we also computed turnover time using Eq. (2) for the long-term field study to take into account the slowing down of the mineralization rate with time. The turnover times of grouped factors were compared using a non-parametric Wilcoxon rank sum test. Interactions between factors on the compiled data were evaluated by multi-way ANOVA using R software (supplementary Table 3 ). Our analysis shows that we do not have any significant interactions between the fac- tors. Therefore, the unbalanced design of the grouped data does not introduce any significant error in the interpretation, and we can evaluate the differences in turnover times associated with these different factors.

\subsubsection{Incubation vs. field study}

Incubation studies have significantly $(p<0.001)$ shorter turnover times (average $55 \mathrm{y}$; range $1-180 \mathrm{y}$ ) than field-based studies (average 353 years; ranges from 90 to 750 years), computed using the one-pool decay model, Eq. (1) (Fig. 3). Short-term decay studies may primarily capture the rapid initial loss of more labile or/and non-charred components, and therefore may not be a good indication of the longterm degradation rates. The two-pool model partly solves this problem, but we had insufficient information to parameterize this model for individual studies; the two-pool model results 
reported above were generated with the combined dataset. The turnover time computed on a combined data set for incubation studies $(n=47)$ using the two-pool model approach showed a low value for regression $\left(r^{2}=0.16\right)$; hence it is not reported here (Supplement Fig. 1). These possible explanations for the short turnover time in incubations also pertain to short-term field experiments (Major et al., 2009). Incubation studies were conducted with fine-sized PyC (Hamer et al., 2004; Major et al., 2009; Nocentini et al., 2010b) at higher or constant room temperature and field capacity moisture content (Baldock and Smernik, 2002; Hilscher et al., 2009; Zimmerman, 2010), which partly explains the accelerated degradation rates and the faster turnover time (Nocentini et al., 2010a).

Long-term field studies provide a more realistic estimation of in situ turnover time of PyC, which not only includes the rapid initial phase but also the phase when the mineralization rate decreases with time. We took advantage of published data from long-term field studies to estimate the turnover time for PyC in situ. It was, however, not possible to conduct a straightforward mass balance for the multi-year field studies, because few of these had data on initial PyC stock and the rate of atmospheric deposition of PyC throughout each study was unknown. The turnover time derived by analysing all the data from long-term field studies $(n=6)$ using the twopool model was $91 \mathrm{y}$ for the fast-cycling pool and $1034 \mathrm{y}$ for the slow-cycling pool, with $49 \%$ in the fast pool $\left(r^{2}=0.51\right)$ (Supplement Fig. 1). Thus, long-term field data indicate that a significant fraction of PyC turns over on roughly centennial scale, which is shorter than previously assumed or estimated (Lehmann et al., 2008; Liang et al., 2008; Kuzyakov et al., 2009). At present, little is known about the underlying mechanisms of PyC degradation on longer time scales. Decomposition under field conditions may be enhanced by freezethaw cycles (Carcaillet, 2001), root growth (Carcaillet and Talon, 1996; Lehmann et al., 2003), fungal hyphae (Hammes and Schmidt, 2009), soil fauna (Ponge et al., 2006), and erosion that exposes PyC to biological and chemical degradation.

\subsubsection{Initial biomass type}

There were two types of initial biomass in the studies we used that were representative for grassland and forest ecosystems, namely grass and wood (Fig. 3). Grass PyC turned over (average $37 \mathrm{y}$, range $2-170 \mathrm{y})$ significantly faster $(p<0.05)$ than wood PyC (average turnover time $=79 \mathrm{y}$, range 2-181 y) in the incubation studies. This is consistent with a previous observation of faster oxidation of grass $\mathrm{PyC}$ as compared to wood, possibly reflecting differences in their chemical structure (Nguyen and Lehmann, 2009). Fourier Transformed Infra Red (FTIR) spectra of grass and wood PyC produced at the same temperature (Keiluweit et al., 2010) show differences in the physical architecture and molecular composition of PyC produced. Knicker et al. (2008) proposed that a significant amount of grass-derived PyC consists of $\mathrm{N}$ heteroaromatic carbon, with the average cluster size of the aromatic units smaller than six rings. In general, this would be consistent with the view that a lignocelluloses-rich substrate like wood is transformed by charring into a more aromatic structure than is the thermally labile hemicellulosic structure of grass (Czimczik et al., 2002). If true, grass PyC would probably be easier to degrade as compared to wood PyC. The influence of initial biomass on chemical structure diminishes with increasing pyrolysis temperature of $\mathrm{PyC}$ (Schneider et al., 2011). Therefore, the chemical and physical structure of $\mathrm{PyC}$ is not directly correlated with or predicable by the structure of the plant substrate for charring.

\subsubsection{Pyrolysis temperature}

The pyrolysis condition under which $\mathrm{PyC}$ is formed also determines its chemical and physical properties and possibly its turnover times. In natural environments, it is unlikely that any one set of formation conditions can be viewed as typical (Brown et al., 2006) and PyC formed during wildfire varies significantly depending on formation conditions (Schmidt and Noack, 2000). In recent years, considerable effort has been expended to characterize PyC produced naturally (Kuhlbusch, 1995; Otto et al., 2006; Smernik et al., 2006; Kaal et al., 2008; Lehmann et al., 2005) and under controlled conditions (Shindo, 1991; Pastorova et al., 1993, 1994; Nishimiya et al., 1998; Hammes et al., 2008a; Cheng and Lehmann, 2009; Keiluweit et al., 2010; Schneider et al., 2010; Zimmerman, 2010). These studies often describe PyC as a continuum from partially charred plant materials to charcoal to soot (Preston and Schmidt, 2006); however, the basic structure of PyC remains similar and consists of condensed aromatic clusters. It has been observed that high temperatures of pyrolysis and thermal ramping rates have major effects on char properties (Mackay and Roberts, 1982; Byrne, 1996; Lewis, 1999; Kercher and Nagle, 2003) and degree of condensation (McBeath and Smernik, 2009; Schneider et al., 2010). Therefore, in this review we analyse the effect of $\mathrm{PyC}$ produced at lower temperature and higher temperature on turnover times, rather than the effect of wildfire $\mathrm{PyC}$ and laboratory-produced $\mathrm{PyC}$ on turnover times.

We chose $400^{\circ} \mathrm{C}$ as temperature threshold based on PyC thermosequence studies (Keiluweit et al., 2010; Schneider et al., 2010), which showed maximum modification in PyC structure around $400^{\circ} \mathrm{C}$. Pyrolysis temperature data were only available for incubation-based studies. Turnover time was significantly shorter $(p<0.05)$ for low temperature, $<400^{\circ} \mathrm{C}$ (average turnover time $=25 \mathrm{y}$, range $2-82 \mathrm{y}$ ), than PyC formed at high temperature, $\geq 400^{\circ} \mathrm{C}$ (average turnover time $=81 \mathrm{y}$, range 2-181 y). Lower-temperature PyC may contain more uncharred material in the initial biomass (Zimmerman, 2010), which may be comparatively more labile than charred biomass and thus results in a faster turnover time. Moreover, PyC formed at lower temperature can have 
greater internal microporosity (Hammes et al., 2008a), allowing easier access to oxidizing agents like water or microbes that facilitate degradation. The degree of condensation increases with higher pyrolysis temperature (Nishimiya et al., 1998; Baldock and Smernik, 2002; McBeath and Smernik, 2009; Schneider et al., 2010) and this could explain the slower turnover of high-temperature PyC.

\subsubsection{Quartz sand and soil medium}

Most incubation studies used either quartz sand with microbial inoculum or fresh soil, and all field studies took place in soil. As a consequence, we only used incubation studies to compare turnover times by medium. PyC has a shorter turnover time in soil (average $=23 \mathrm{y}$, range $2-109 \mathrm{y}$ ) than in quartz sand (average $=73 \mathrm{y}$, range $2-181 \mathrm{y}$ ). Quartz sand probably has a higher permeability and oxygen level than soil (Zimmerman, 2010), whereas soil as a medium should yield more realistic values because (among other reasons) it holds a larger range of microbial populations than that afforded by a microbial inoculum (Riis et al., 1998). The faster turnover time in soil may reflect the role of microbial community in PyC degradation. However, the influence of microbial community composition on $\mathrm{PyC}$ degradation is poorly understood (Pietikainen et al., 2000; Czimczik and Masiello, 2007). In addition, soils contain non-pyrogenic organic matter that may act as primer for the faster degradation of $\mathrm{PyC}$ (Hamer et al., 2004).

$\mathrm{PyC}$ is also known to interact with soil minerals (Piccolo et al., 1997; Glaser et al., 2000; Brodowski et al., 2005; Liang et al., 2008), in some cases resulting in aggregation (Brodowski et al., 2006; Vasilyeva et al., 2011) and stabilization in the soil system. However, short-term incubation studies might not capture the stabilizing effects of organo-mineral interactions.

\subsubsection{Climate}

Climate, including temperature and moisture, influences SOM and PyC decomposition, but there were insufficient data with which we could analyse its effect on turnover time. A few studies observed a positive correlation between mean annual temperature of the field site and PyC degradation (Glaser and Amelung, 2003; Cheng et al., 2008a) but not with mean annual precipitation (Cheng et al., 2008a). Further, Nguyen et al. (2010) also showed that degradation rates of $\mathrm{PyC}$ are accelerated with increasing temperature. Faster turnover of $<100$ years observed in tropical (Nguyen et al., 2008) and subtropical climate (Bird et al., 1999) was attributed to the more favourable climate. Slower degradation rates could be expected in boreal forests (Preston and Schmidt, 2006). However, in a boreal forest (Ohlson et al., 2009) PyC content decreased to the concentration of the surrounding organic soil matrix in about 100 years. Thus, we need to directly examine a range of climatic conditions to understand the influence of environment on $\mathrm{PyC}$ turnover time.

\subsection{Discussion}

Some observations of PyC content or radiocarbon age in soil have interpreted $\mathrm{PyC}$ as recalcitrant with turnover times in soil of millennia. Applying a simple modelling approach to a broad set of published data, we find that turnover of PyC in soil occurs faster, on a centennial time scale. This is in accordance with Hammes et al. (2008b), Major et al. (2009) and Kuzyakov et al. (2009), but significantly shorter than the turnover time estimated in an incubation study (Zimmerman, 2010 ) or inferred from the radiocarbon age of $\mathrm{PyC}$ in some studies (Pessenda et al., 2001; Schmidt et al., 2002; Liang et al., 2008). There are two considerations that help reconcile the apparent inconsistency.

First, the apparent inconsistency of $\mathrm{PyC}$ radiocarbon ages with the estimated turnover time of PyC could be explained by the "inbuilt age" of a piece of charcoal produced during fire because the wood may have been old at the time of the fire (Gavin et al., 2003). Few trees live to be a thousand years old, so it is likely that a piece of charcoal that is thousands of years old has been in the soil for $>1000$ years. Moreover, it is difficult to translate the radiocarbon age of an isolated piece of charcoal to a turnover time without knowledge of the initial stock or input of $\mathrm{PyC}$, leading to uncertainty in the estimate.

Second, it is likely that some PyC stays in some soils for many thousands of years. The two-pool model shows that the $\mathrm{PyC}$ experiments analysed contained fairly slow-cycling material, even if the bulk behaviour was well described with a shorter turnover time. Studies of bulk soil organic matter find a spectrum of turnover times, with persistence depending on the compound chemistry and its physico-chemical state in soil, such as interaction with minerals or protection inside aggregate structures (Schmidt et al., 2011) that result in turnover times up to thousands of years. We would expect $\mathrm{PyC}$ to have similar behaviour in soil (Torn et al., 2002).

A caveat on our turnover time results is that at present, most controlled studies of PyC are relatively short-term and may be biased towards rapid turnover times, given the initial decomposition dynamics that diminish over time (Kuzyakov et al., 2009) as the labile component is metabolized (Smith et al., 2010). Our knowledge of the later stages of degradation is much poorer. Therefore, our estimates using a one-pool model could overestimate the rate of $\mathrm{PyC}$ degradation (and underestimate turnover time). The two-pool decay model provides a better fit to the data than the one-pool model, and does show a more persistent fraction of PyC. It has been suggested that physical protection and interactions with soil minerals play a significant part in long-term PyC stability (Brodowski et al., 2006; Glaser et al., 2000) and forming what we called the slow PyC pool. However, the duration 
of available data is too short to quantify longer decay time scales.

The differences in turnover times among studies could also be due to the interplay of different decomposition or stabilization mechanisms at a local scale, resulting in differences in the rate of degradation. A combination of physical, chem$\mathrm{ical}$, and microbial processes can play a role in PyC degradation. However, these degradation processes have not yet been studied in combination, and questions remain as to the interaction of these processes and the importance of PyC chemistry, soil conditions, and microbial activity in controlling the likelihood of $\mathrm{PyC}$ degradation or persistence.

\section{Conclusion and future research}

PyC comprises an array of compounds and is present in different environmental matrices; thus, there is not a single rate of decomposition to describe $\mathrm{PyC}$ dynamics in all soils and conditions. Nevertheless, based on this analysis of published data, the nominal turnover time of $\mathrm{PyC}$ is shorter than previously assumed, on order of hundreds of years. Over a range of $\mathrm{PyC}$ properties and edaphic conditions, $\mathrm{PyC}$ was found to degrade in soil, and there was consistent evidence that PyC does not act as an inert or universally recalcitrant compound in soil. To better understand $\mathrm{PyC}$ as a potential dynamic link between fire, soil, and the carbon cycle, and to investigate its potential for carbon sequestration strategies, we recommend the initiation of long-term PyC degradation field experiments, in different climate and soil types, to address the decomposition dynamics of aging $\mathrm{PyC}$, as well as research to identify underlying mechanisms of $\mathrm{PyC}$ degradation and the factors controlling its stability in soil.

\section{Supplementary material related to this article is available online at: http://www.biogeosciences.net/9/ 2847/2012/bg-9-2847-2012-supplement.pdf.}

Acknowledgements. The Swiss National Science Foundation sponsored the research. This work was partially supported by the Office of Science of the US Department of Energy under Contract No. DE-AC02-05CH11231. We thank the Soil and Biogeography reading group, University of Zurich, for providing helpful comments on the manuscript. We also thank two anonymous reviewers for their helpful comments.

Author contributions. N.S. assembled the data, N.S. and S.A. analyzed the data, and all authors contributed to the research design and the text.

Additional information. The authors declare no competing financial interests. Supplementary information accompanies this paper. Correspondence and requests for materials should be addressed to NS.
Edited by: X. Wang

\section{References}

Abiven, S., Hengartner, P., Schneider, M. P. W., Singh, N., and Schmidt, M. W. I.: Pyrogenic carbon soluble fraction is larger and more aromatic in aged charcoal than in fresh charcoal, Soil Biol. Biochem., 43, 1615-1617, doi:10.1016/J.Soilbio.2011.03.027, 2011.

Amelung, W., Brodowski, S., Sandhage-Hofmann, A., and Bol, R.: Combining Biomarker with Stable Isotope Analyses for Assessing the Transformation and Turnover of Soil Organic Matter, Advances in Agronomy, 100, 155-250, doi:10.1016/S00652113(08)00606-8, 2008.

Baldock, J. A. and Smernik, R. J.: Chemical composition and bioavailability of thermally, altered Pinus resinosa (Red Pine) wood, Organic Geochemistry, 33, 1093-1109, Pii S014666380(02)0062-1, 2002.

Bird, M. I., Moyo, C., Veenendaal, E. M., Lloyd, J., and Frost, P.: Stability of elemental carbon in a savanna soil, Global Biogeochemical Cycles, 13, 923-932, 1999.

Brodowski, S.: Origin, function, and reactivity of black carbon in the arable soil environment, $\mathrm{PhD}$ Thesis, Institut für Bodenkunde, Bonn, 183, 2005.

Brodowski, S., Amelung, W., Haumaier, L., Abetz, C., and Zech, W.: Morphological and chemical properties of black carbon in physical soil fractions as revealed by scanning electron microscopy and energy-dispersive X-ray spectroscopy, Geoderma, 128, 116-129, doi:10.1016/J.Geoderma.2004.12.019, 2005.

Brodowski, S., John, B., Flessa, H., and Amelung, W.: Aggregateoccluded black carbon in soil, European Journal of Soil Science, 57, 539-546, doi:10.1111/j.1365-2389.2006.00807.x, 2006.

Brown, R. A., Kercher, A. K., Nguyen, T. H., Nagle, D. C., and Ball, W. P.: Production and characterization of synthetic wood chars for use as surrogates for natural sorbents, Organic Geochemistry, 37, 321-333, doi:10.1016/J.Orggeochem.2005.10.008, 2006.

Bruun, S., Jensen, E. S., and Jensen, L. S.: Microbial mineralization and assimilation of black carbon: Dependency on degree of thermal alteration, Organic Geochemistry, 39, 839-845, doi:10.1016/J.Orggeochem.2008.04.020, 2008.

Burnham, K. P. and Anderson, D. R.: Model selection and multimodel inference: a practical information-theoretic approach, Springer, New York, 488 pp., 2002.

Byrne, C.: Polymer, ceramic and carbon composites derived from wood, PhD, Johns Hopkins University, Baltimore, 1996.

Carcaillet, C.: Are Holocene wood-charcoal fragments stratified in alpine and subalpine soils? Evidence from the Alps based on AMS C-14 dates, Holocene, 11, 231-242, 2001.

Carcaillet, C. and Talon, B.: A view of the wood charcoal stratigraphy and dating in soil: A case study of some soils from the French Alps., Geographie Physique Et Quaternaire, 50, 233-244, 1996.

Cheng, C. H. and Lehmann, J.: Ageing of black carbon along a temperature gradient, Chemosphere, 75, 1021-1027, doi:10.1016/j.chemosphere.2009.01.045, 2009.

Cheng, C. H., Lehmann, J., Thies, J. E., Burton, S. D., and Engelhard, M. H.: Oxidation of black carbon by biotic and abiotic processes, Organic Geochemistry, 37, 1477-1488, doi:10.1016/j.orggeochem.2006.06.022, 2006. 
Cheng, C. H., Lehmann, J., and Engelhard, M. H.: Natural oxidation of black carbon in soils: Changes in molecular form and surface charge along a climosequence, Geochim. Cosmochim. Ac., 72, 1598-1610, doi:10.1016/J.Gca.2008.01.010, 2008a.

Cheng, C. H., Lehmann, J., Thies, J. E., and Burton, S. D.: Stability of black carbon in soils across a climatic gradient, J. Geophys. Res.-Biogeosciences, 113, G02027, doi:10.1029/2007jg000642, 2008b.

Czimczik, C. I. and Masiello, C. A.: Controls on black carbon storage in soils, Global Biogeochem. Cycles, 21, Gb3005, doi:10.1029/2006gb002798, 2007.

Czimczik, C. I., Preston, C. M., Schmidt, M. W. I., Werner, R. A., and Schulze, E. D.: Effects of charring on mass, organic carbon, and stable carbon isotope composition of wood, Organic Geochemistry, 33, 1207-1223, Pii S0146-6380(02)00137-7, 2002.

Derrien, D. and Amelung, W.: Computing the mean residence time of soil carbon fractions using stable isotopes: impacts of the model framework, European Journal of Soil Science, 62, 237252, doi:10.1111/j.1365-2389.2010.01333.x, 2011.

Flannigan, M., Amiro, B., Logan, K., Stocks, B., and Wotton, B.: Forest Fires and Climate Change in the 21st Century, Mitigation and Adaptation Strategies for Global Change, 11, 847-859, doi:10.1007/s11027-005-9020-7, 2006.

Forbes, M. S., Raison, R. J., and Skjemstad, J. O.: Formation, transformation and transport of black carbon (charcoal) in terrestrial and aquatic ecosystems, Sci. Total Environ., 370, 190-206, doi:10.1016/j.scitotenv.2006.06.007, 2006.

Franklin, R. E.: Crystallite Growth in Graphitizing and NonGraphitizing Carbons, Proceedings of the Royal Society of London Series a-Mathematical and Physical Sciences, 209, 196-218, 1951.

Gavin, D. G., Brubaker, L. B., and Lertzman, K. P.: Holocene fire history of a coastal temperate rain forest based on soil charcoal radiocarbon dates, Ecology, 84, 186-201, 2003.

Glaser, B.: Compound-specific stable-isotope (delta C-13) analysis in soil science, J. Plant Nutr. Soil Sci.-Z. Pflanzenernahr. Bodenkd., 168, 633-648, 2005.

Glaser, B.: Prehistorically modified soils of central Amazonia: a model for sustainable agriculture in the twenty-first century, Philos. T. R. Soc. B, 362, 187-196, doi:10.1098/Rstb.2006.1978, 2007.

Glaser, B. and Amelung, W.: Pyrogenic carbon in native grassland soils along a climosequence in North America, Global Biogeochem. Cycles, 17, 1064, doi:10.1029/2002gb002019, 2003.

Glaser, B. and Birk, J. J.: State of the scientific knowledge on properties and genesis of Anthropogenic Dark Earths in Central Amazonia (terra preta de Indio), Geochim. Cosmochim. Acta, 82, 3951, doi:10.1016/J.Gca.2010.11.029, 2012.

Glaser, B., Balashov, E., Haumaier, L., Guggenberger, G., and Zech, W.: Black carbon in density fractions of anthropogenic soils of the Brazilian Amazon region, Organic Geochemistry, 31, 669678, 2000.

Goldberg, E. D.: Black carbon in the environment: properties and distribution, John Wiley and Sons, New York, 198 pp., 1985.

Hamer, U., Marschner, B., Brodowski, S., and Amelung, W.: Interactive priming of black carbon and glucose mineralisation, Organic Geochemistry, 35, 823-830, doi:10.1016/J.Orggeochem.2004.03.003, 2004.
Hammes, K. and Schmidt, M. W. I.: Changes of biochar in soil, in: Biochar for environmental Management, edited by: Lehmann, J., and Joseph, S., Biochar for Environmental Management, Earthscan, London, 169-182, 2009.

Hammes, K., Smernik, R. J., Skjemstad, J. O., and Schmidt, M. W. I.: Characterisation and evaluation of reference materials for black carbon analysis using elemental composition, colour, BET surface area and C-13 NMR spectroscopy, Appl. Geochemistry, 23, 2113-2122, doi:10.1016/J.Apgeochem.2008.04.023, 2008a.

Hammes, K., Torn, M. S., Lapenas, A. G., and Schmidt, M. W. I.: Centennial black carbon turnover observed in a Russian steppe soil, Biogeosciences, 5, 1339-1350, doi:10.5194/bg-51339-2008, 2008b.

Hilscher, A. and Knicker, H.: Degradation of grass-derived pyrogenic organic material, transport of the residues within a soil column and distribution in soil organic matter fractions during a 28 month microcosm experiment, Organic Geochemistry, 42, 42-54, doi:10.1016/J.Orggeochem.2010.10.005, 2011.

Hilscher, A., Heister, K., Siewert, C., and Knicker, H.: Mineralisation and structural changes during the initial phase of microbial degradation of pyrogenic plant residues in soil, Organic Geochemistry, 40, 332-342, doi:10.1016/j.orggeochem.2008.12.004, 2009.

Hockaday, W. C., Grannas, A. M., Kim, S., and Hatcher, P. G.: Direct molecular evidence for the degradation and mobility of black carbon in soils from ultrahigh-resolution mass spectral analysis of dissolved organic matter from a fireimpacted forest soil, Organic Geochemistry, 37, 501-510, doi:10.1016/J.Orggeochem.2005.11.003, 2006.

Kaal, J., Brodowski, S., Baldock, J. A., Nierop, K. G. J., and Cortizas, A. M.: Characterisation of aged black carbon using pyrolysis-GC/MS, thermally assisted hydrolysis and methylation (THM), direct and cross-polarisation C-13 nuclear magnetic resonance (DP/CP NMR) and the benzenepolycarboxylic acid (BPCA) method, Organic Geochemistry, 39, 1415-1426, doi:10.1016/J.Orggeochem.2008.06.011, 2008.

Keiluweit, M., Nico, P. S., Johnson, M. G., and Kleber, M.: Dynamic Molecular Structure of Plant Biomass-Derived Black Carbon (Biochar), Environ. Sci. Technol., 44, 1247-1253, doi:10.1021/es9031419, 2010.

Kercher, A. K. and Nagle, D. C.: Microstructural evolution during charcoal carbonization by X-ray diffraction analysis, Carbon, 41 , 15-27, 2003.

Knicker, H.: Pyrogenic Organic Matter in Soil: Its Origin and Occurrence, its Chemistry and Survival in Soil Environments, Quaternary International, 243, 251-263, doi:10.1016/j.quaint.2011.02.037, 2011.

Knicker, H., Hilscher, A., Gonzalez-Vila, F. J., and Almendros, G.: A new conceptual model for the structural properties of char produced during vegetation fires, Organic Geochemistry, 39, 935939, doi:10.1016/J.Orggeochem.2008.03.021, 2008.

Krull, E. S., Swanston, C. W., Skjemstad, J. O., and McGowan, J. A.: Importance of charcoal in determining the age and chemistry of organic carbon in surface soils, J. Geophys. Res.-Biogeosciences, 111, G04001, doi:10.1029/2006jg000194, 2006.

Kuhlbusch, T. A. J.: Methods for determining black carbon in residues of vegetation fires, Environ. Sci. Technol., 29, 26952702, 1995. 
Kuhlbusch, T. A. J.: Black carbon and the carbon cycle, Science, 280, 1903-1904, 1998.

Kuzyakov, Y., Subbotina, I., Chen, H. Q., Bogomolova, I., and $\mathrm{Xu}, \mathrm{X}$. L.: Black carbon decomposition and incorporation into soil microbial biomass estimated by C-14 labeling, Soil Biol. Biochem., 41, 210-219, 2009.

Lehmann, J., da Silva, J. P., Steiner, C., Nehls, T., Zech, W., and Glaser, B.: Nutrient availability and leaching in an archaeological Anthrosol and a Ferralsol of the Central Amazon basin: fertilizer, manure and charcoal amendments, Plant and Soil, 249, 343-357, 2003.

Lehmann, J., Liang, B. Q., Solomon, D., Lerotic, M., Luizao, F., Kinyangi, J., Schafer, T., Wirick, S., and Jacobsen, C.: Nearedge X-ray absorption fine structure (NEXAFS) spectroscopy for mapping nano-scale distribution of organic carbon forms in soil: Application to black carbon particles, Global Biogeochem. Cycles, 19, Gb1013, doi:10.1029/2004gb002435, 2005.

Lehmann, J., Gaunt, J., and Rondon, M.: Bio-Char sequestration in terrestrial ecosystems - A review, Mitigation and Adaptation Strategies for Global Change, 11, 403-427, doi:10.1007/s11027005-9006-5, 2006.

Lehmann, J., Skjemstad, J., Sohi, S., Carter, J., Barson, M., Falloon, P., Coleman, K., Woodbury, P., and Krull, E.: Australian climate-carbon cycle feedback reduced by soil black carbon, Nature Geosci., 1, 832-835, doi:10.1038/ngeo358, 2008.

Lewis, A. C.: Production and Characterization of Structural Active Carbon from Wood Precursors, Johns Hopkins University, 192 pp., 1999.

Liang, B., Lehmann, J., Solomon, D., Sohi, S., Thies, J. E., Skjemstad, J. O., Luizao, F. J., Engelhard, M. H., Neves, E. G., and Wirick, S.: Stability of biomass-derived black carbon in soils, Geochim. Cosmochim. Ac., 72, 6069-6078, doi:10.1016/j.gca.2008.09.028, 2008.

Mackay, D. M. and Roberts, P. V.: The Dependence of Char and Carbon Yield on Lignocellulosic Precursor Composition, Carbon, 20, 87-94, 1982.

Major, J., Lehmann, J., Rondon, M., and Goodale, C.: Fate of soil-applied black carbon: downward migration, leaching and soil respiration, Glob. Change Biol., 16, 1366-1379, doi:10.1111/j.1365-2486.2009.02044.x, 2009.

Marris, E.: Putting the carbon back: Black is the new green, Nature, 442, 624-626, doi:10.1038/442624a, 2006.

Marschner, B.: How relevant is recalcitrance for the stabilization of organic matter in soils?, Journal of plant nutrition and soil science, 171, 91-110, doi:10.1002/jpln.200700049, 2008.

McBeath, A. V. and Smernik, R. J.: Variation in the degree of aromatic condensation of chars, Organic Geochemistry, 40, 11611168, doi:10.1016/J.Orggeochem.2009.09.006, 2009.

Nguyen, B. T. and Lehmann, J.: Black carbon decomposition under varying water regimes, Organic Geochemistry, 40, 846-853, doi:10.1016/j.orggeochem.2009.05.004, 2009.

Nguyen, B. T., Lehmann, J., Kinyangi, J., Smernik, R., Riha, S. J., and Engelhard, M. H.: Long-term black carbon dynamics in cultivated soil, Biogeochemistry, 89, 295-308, doi:10.1007/S10533-008-9220-9, 2008.

Nguyen, B. T., Lehmann, J., Hockaday, W. C., Joseph, S., and Masiello, C. A.: Temperature Sensitivity of Black Carbon Decomposition and Oxidation, Environ. Sci. Technol., 44, 33243331, doi:10.1021/es903016y, 2010.
Nishimiya, K., Hata, T., Imamura, Y., and Ishihara, S.: Analysis of chemical structure of wood charcoal by X-ray photoelectron spectroscopy, J. Wood Sci., 44, 56-61, 1998.

Nocentini, C., Certini, G., Knicker, H., Francioso, O., and Rumpel, C.: Nature and reactivity of charcoal produced and added to soil during wildfire are particle-size dependent, Organic Geochemistry, 41, 682-689, doi:10.1016/J.Orggeochem.2010.03.010, 2010a.

Nocentini, C., Guenet, B., Di Mattia, E., Certini, G., Bardoux, G., and Rumpel, C.: Charcoal mineralisation potential of microbial inocula from burned and unburned forest soil with and without substrate addition, Soil Biol. Biochem., 42, 1472-1478, doi:10.1016/J.Soilbio.2010.05.009, 2010b.

Ohlson, M., Dahlberg, B., Okland, T., Brown, K. J., and Halvorsen, R.: The charcoal carbon pool in boreal forest soils, Nature Geosci., 2, 692-695, doi:10.1038/Ngeo617, 2009.

Otto, A., Gondokusumo, R., and Simpson, M. J.: Characterization and quantification of biomarkers from biomass burning at a recent wildfire site in Northern Alberta, Canada, Appl. Geochemistry, 21, 166-183, doi:10.1016/J.Apgeochem.2005.09.007, 2006.

Parton, W. J., Stewart, J. W. B., and Cole, C. V.: Dynamics of C, N, P and S in Grassland Soils - a Model, Biogeochemistry, 5, 109-131, 1988.

Pastorova, I., Arisz, P. W., and Boon, J. J.: Preservation of D-Glucose-Oligosaccharides in Cellulose Chars, Carbohydrate Res., 248, 151-165, 1993.

Pastorova, I., Botto, R. E., Arisz, P. W., and Boon, J. J.: Cellulose char structure- A combined analytical PY-GC-MS FTIR, and NMR-study, Carbohydrate Res., 262, 27-47, 1994.

Pessenda, L. C. R., Gouveia, S. E. M., and Aravena, R.: Radiocarbon dating of total soil organic matter and humin fraction and its comparison with C-14 ages of fossil charcoal, Radiocarbon, 43, 595-601, 2001.

Piccolo, A., Pietramellara, G., and Mbagwu, J. S. C.: Use of humic substances as soil conditioners to increase aggregate stability, Geoderma, 75, 267-277, 1997.

Pietikainen, J., Kiikkila, O., and Fritze, H.: Charcoal as a habitat for microbes and its effect on the microbial community of the underlying humus, Oikos, 89, 231-242, 2000.

Ponge, J. F., Topoliantz, S., Ballof, S., Rossi, J. P., Lavelle, P., Betsch, J. M., and Gaucher, P.: Ingestion of charcoal by the Amazonian earthworm Pontoscolex corethrurus: A potential for tropical soil fertility, Soil Biol. Biochem., 38, 2008-2009, doi:10.1016/J.Soilbio.2005.12.024, 2006.

Potter, M. C.: Bacteria as agents in the oxidation of amorphous carbon, P R Soc Lond B-Conta, 80, 239-259, 1908.

Preston, C. M. and Schmidt, M. W. I.: Black (pyrogenic) carbon: a synthesis of current knowledge and uncertainties with special consideration of boreal regions, Biogeosciences, 3, 397-420, doi:10.5194/bg-3-397-2006, 2006.

Riis, V., Lorbeer, H., and Babel, W.: Extraction of microorganisms from soil: Evaluation of the efficiency by counting methods and activity measurements, Soil Biol. Biochem., 30, 1573-1581, doi:10.1016/s0038-0717(97)00232-0, 1998.

Rumpel, C., Chaplot, V., Planchon, O., Bernadou, J., Valentin, C., and Mariotti, A.: Preferential erosion of black carbon on steep slopes with slash and burn agriculture, Catena, 65, 30-40, doi:10.1016/J.Catena.2005.09.005, 2006. 
Schmid, E. M., Skjemstad, J. O., Glaser, B., Knicker, H., and KogelKnabner, I.: Detection of charred organic matter in soils from a Neolithic settlement in Southern Bavaria, Germany, Geoderma, 107, 71-91, Pii S0016-7061(01)00139-2, 2002.

Schmidt, M. W. I., Skjemstad, J. O., Gehrt, E., and Kogel-Knabner, I.: Charred organic carbon in German chernozemic soils, European Journal of Soil Science, 50, 351-365, 1999.

Schmidt, M. W. I. and Noack, A. G.: Black carbon in soils and sediments: Analysis, distribution, implications, and current challenges, Global Biogeochem. Cycles, 14, 777-793, 2000.

Schmidt, M. W. I., Skjemstad, J. O., and Jager, C.: Carbon isotope geochemistry and nanomorphology of soil black carbon: Black chernozemic soils in central Europe originate from ancient biomass burning, Global Biogeochem. Cycles, 16, 1123, doi:10.1029/2002GB001939, 2002.

Schmidt, M. W. I., Torn, M. S., Abiven, S., Dittmar, T., Guggenberger, G., Janssens, I. A., Kleber, M., Kogel-Knabner, I., Lehmann, J., Manning, D. A. C., Nannipieri, P., Rasse, D. P., Weiner, S., and Trumbore, S. E.: Persistence of soil organic matter as an ecosystem property, Nature, 478, 49-56, doi:10.1038/Nature10386, 2011.

Schneider, M. P. W., Hilf, M., Vogt, U. F., and Schmidt, M. W. I.: The benzene polycarboxylic acid (BPCA) pattern of wood pyrolyzed between 200 degrees $\mathrm{C}$ and 1000 degrees C, Organic Geochemistry, 41, 1082-1088, doi:10.1016/J.Orggeochem.2010.07.001, 2010.

Schneider, M. P. W., Smittenberg, R. H., Dittmar, T., and Schmidt, M. W. I.: Comparison of gas with liquid chromatography for the determination of benzenepolycarboxylic acids as molecular tracers of black carbon, Organic Geochemistry, 42, 275-282, doi:10.1016/j.orggeochem.2011.01.003, 2011.

Seifritz, W.: Should We Store Carbon in Charcoal, International Journal of Hydrogen Energy, 18, 405-407, 1993.

Seiler, W. and Crutzen, P. J.: Estimates of Gross and Net Fluxes of Carbon between the Biosphere and the Atmosphere from Biomass Burning, Climatic Change, 2, 207-247, 1980.

Shindo, H.: Elementary composition, humus composition, and decomposition in soil of charred grassland plants Soil Science and Plant Nutrition, 37, 651-657, 1991.
Shneour, E. A.: Oxidation of graphitic carbon in certain soils, Science, 151, 991-992, doi:10.1126/science.151.3713.991, 1966.

Skjemstad, J. O., Clarke, P., Taylor, J. A., Oades, J. M., and McClure, S. G.: The chemistry and nature of protected carbon in soil, Australian Journal of Soil Research, 34, 251-271, 1996.

Skjemstad, J. O., Reicosky, D. C., Wilts, A. R., and McGowan, J. A.: Charcoal carbon in US agricultural soils, Soil Science Society of America Journal, 66, 1249-1255, 2002.

Smernik, R. J., Kookana, R. S., and Skjemstad, J. O.: NMR characterization of $\mathrm{C}-13$-benzene sorbed to natural and prepared charcoals, Environ. Sci. Technol., 40, 1764-1769, doi:10.1021/Es051895o, 2006.

Smith, J. L., Collins, H. P., and Bailey, V. L.: The effect of young biochar on soil respiration, Soil Biol. Biochem., 42, 2345-2347, doi:10.1016/J.Soilbio.2010.09.013, 2010.

Spokas, K. A.: Review of the stability of biochar in soils: predictability of O:C molar ratios, Carbon Management, 1, 289303, 2010.

Torn, M. S., Lapenis, A. G., Timofeev, A., Fischer, M. L., Babikov, B. V., and Harden, J. W.: Organic carbon and carbon isotopes in modern and 100-year-old-soil archives of the Russian steppe, Glob. Change Biol., 8, 941-953, 2002.

Trumbore, S.: Age of soil organic matter and soil respiration: Radiocarbon constraints on belowground $\mathrm{C}$ dynamics, Ecol. Appl., 10, 399-411, 2000.

Updegraff, K., Pastor, J., Bridgham, S. D., and Johnston, C. A.: Environmental and Substrate Controls over Carbon and Nitrogen Mineralization in Northern Wetlands, Ecol. Appl., 5, 151-163, 1995.

Vasilyeva, N. A., Abiven, S., Milanovskiy, E. Y., Hilf, M., Rizhkov, O. V., and Schmidt, M. W. I.: Pyrogenic carbon quantity and quality unchanged after 55 years of organic matter depletion in a Chernozem, Soil Biol. Biochem., 43, 1985-1988, doi:10.1016/J.Soilbio.2011.05.015, 2011.

Westerling, A. L., Hidalgo, H. G., Cayan, D. R., and Swetnam, T. W.: Warming and earlier spring increase western US forest wildfire activity, Science, 313, 940-943, doi:10.1126/Science.1128834, 2006.

Zimmerman, A. R.: Abiotic and Microbial Oxidation of Laboratory-Produced Black Carbon (Biochar), Environ. Sci. Technol., 44, 1295-1301, doi:10.1021/es903140c, 2010. 